\title{
Properties of Zinc Borosilicate Glasses
}

\section{Edgar H. Hamilton, Roy M. Waxler, and Joseph M. Nivert, Jr.}

\begin{abstract}
The glass-forming region of the system $\mathrm{ZnO}-\mathrm{B}_{2} \mathrm{O}_{3}-\mathrm{SiO}_{2}$ was surveyed. Glasses were made with compositions within the following limits in mole percent: 50 to $62.5 \mathrm{ZnO}, 20$ to $43.5 \mathrm{~B}_{2} \mathrm{O}_{3}$, and 0 to $20 \mathrm{SiO}_{2}$. They can be melted and poured below $1,400^{\circ} \mathrm{C}$. The glasses have low coefficients of thermal expansion, high values of elastic moduli and Poisson's ratio, and refractive indices from 1.6409 to 1.6798 .
\end{abstract}

\section{Introduction}

In a search for heat-resistant glasses, for which a low coefficient of thermal expansion is desirable, it was found that Winklemann [1] ${ }^{2}$ reported a low, expansion zinc borate glass containing 41 percent of $\mathrm{B}_{2} \mathrm{O}_{3}$ and 59 percent of $\mathrm{ZnO}$ by weight. He reported a coefficient of cubic expansion of $110 \times 10^{-7}$ over the temperature range of 10.35 to $92.88^{\circ} \mathrm{C}$, which is equivalent to a coefficient of linear expansion of $3.7 \times 10^{-6}$. The glass has been reported to have other extreme properties including great hardness, large values of elastic moduli, and Poisson's ratio [1, p. 193]. A glass-forming system, with a glass that is so highly recommended, seemed worthy of further study to determine if there were other glasses with similar or more desirable properties.

E. Ingerson, G. W. Morey, and O. F. Tuttle [2] surveyed the $\mathrm{ZnO}-\mathrm{B}_{2} \mathrm{O}_{3}$ and $\mathrm{ZnO}-\mathrm{B}_{2} \mathrm{O}_{3}-\mathrm{SiO}_{2}$ systems and identified two zinc borate compounds, $\mathrm{ZnO} \cdot \mathrm{B}_{2} \mathrm{O}_{3}$ and $5 \mathrm{ZnO} \cdot 2 \mathrm{~B}_{2} \mathrm{O}_{3}$, and a very large region of twoliquid immiscibility. They found that $\mathrm{ZnO} \cdot \mathrm{B}_{2} \mathrm{O}_{3}$ has an extremely flat primary field - so flat that the determined values of liquidus temperature within the field were all the same, $1,000^{\circ} \mathrm{C}$, within the limits of error of their determination. The $e x-$ tremely flat primary field indicates a high degree of dissociation of $\mathrm{ZnO} \cdot \mathrm{B}_{2} \mathrm{O}_{3}$ at the liquidus. In a number of other multicomponent systems the regions where stable glasses are obtained are in and adjacent to flat primary fields [3]. The $\mathrm{ZnO}-\mathrm{SiO}_{2}$ system was studied by E. N. Bunting [4] who identified one compound, $2 \mathrm{ZnO} \cdot \mathrm{SiO}_{2}$.

\section{Experimental Procedure}

The glasses were made in 500-g melts from batch materials of sufficient purity to satisfy the requirements for optical glass. The melts were made in platinum crucibles and stirred with platinum-10 percent-rhodium propeller-type stirrers. 'The details of the melting procedure are published elsewhere $[5,6]$. The sag points (accurate to $\pm 7^{\circ} \mathrm{C}$ ) [7] of the glasses were used to establish annealing temperatures from which the glasses were cooled at $2.5^{\circ} \mathrm{C}$ per hour to $350^{\circ} \mathrm{C}$. Refractive indices were measured with the Grauer refractometer [8] on small cubes cut from the annealed glasses. With this apparatus the refractive indices can be determined to $\pm 2 \times 10^{-5}$ without additional processing of the glass specimen.

1 The work described in this report was sponsored by the Wright Air Develop-
ment Center, United States Air Force. ment Center, United States Air Force.

${ }^{2}$ Figures in brackets indicate the literature references at the end of this paper.
The liquidus temperature of each glass was determined by a temperature gradient method [9]. The probable error of a single determination is $\pm 4^{\circ} \mathrm{C}$, but the absolute error in the present data may be greater. Comparison with the data of Ingerson et al., to be discussed later, indicates that the error is less than $30^{\circ} \mathrm{C}$. The thermal expansions of selected glasses were determined to within $\pm 0.1 \times 10^{-6}$ by an interferometric method [10]. Chemical durability was determined by the interferometric method of Hubbard and Hamilton [11]. Elastic moduli were measured by the dynamic method described by Spinner [12]. The accuracy of a single determination is \pm 0.4 percent for Young's and Shear moduli, and \pm 1 percent for Poisson's ratio.

The compositions listed in table 1 are calculated from the batch formulations.

The $\mathrm{ZnO}$ and $\mathrm{SiO}_{2}$ contents of four of the glasses were determined by chemical analysis. The calculated and analyzed compositions of these glasses are compared in table 2. The results indicate that the changes in composition during melting of the glasses usually were less than 0.5 mole percent, but for a few of the glasses they may have been as high as 1 mole percent.

\section{Results and Discussion}

\subsection{Glass-Forming Region of the System $\mathrm{ZnO}-\mathrm{B}_{2} \mathrm{O}_{3}$ - $\mathrm{SiO}_{2}$}

The compositions of the melts are given in table 1 and are plotted in figure 1 . Clear binary zinc borate glasses were made containing from 50 to 60 mole percent of $\mathrm{ZnO}$. This composition range coincides with that of the extremely flat primary field of $\mathrm{ZnO} \cdot \mathrm{B}_{2} \mathrm{O}_{3}$ as determined by Ingerson et al. [2]. All of the glasses could be melted below $1,400^{\circ} \mathrm{C}$. The melts were very fluid and easily fined.

\subsection{Liquidus Temperatures}

The liquidus temperatures of many of the glasses are given in table 1 . There is a gradual change in the composition of the glasses at and above their liquidus temperatures. The length of time that a sample is held in this temperature range will have a bearing on the liquidus temperature obtained. Successively higher values were obtained on repeat determinations. The liquidus values given in the table are the highest temperatures at which crystals were observed after a 30 -min holding period. The 
TABLE 1. Compositions and properties of zinc borosilicate glasses

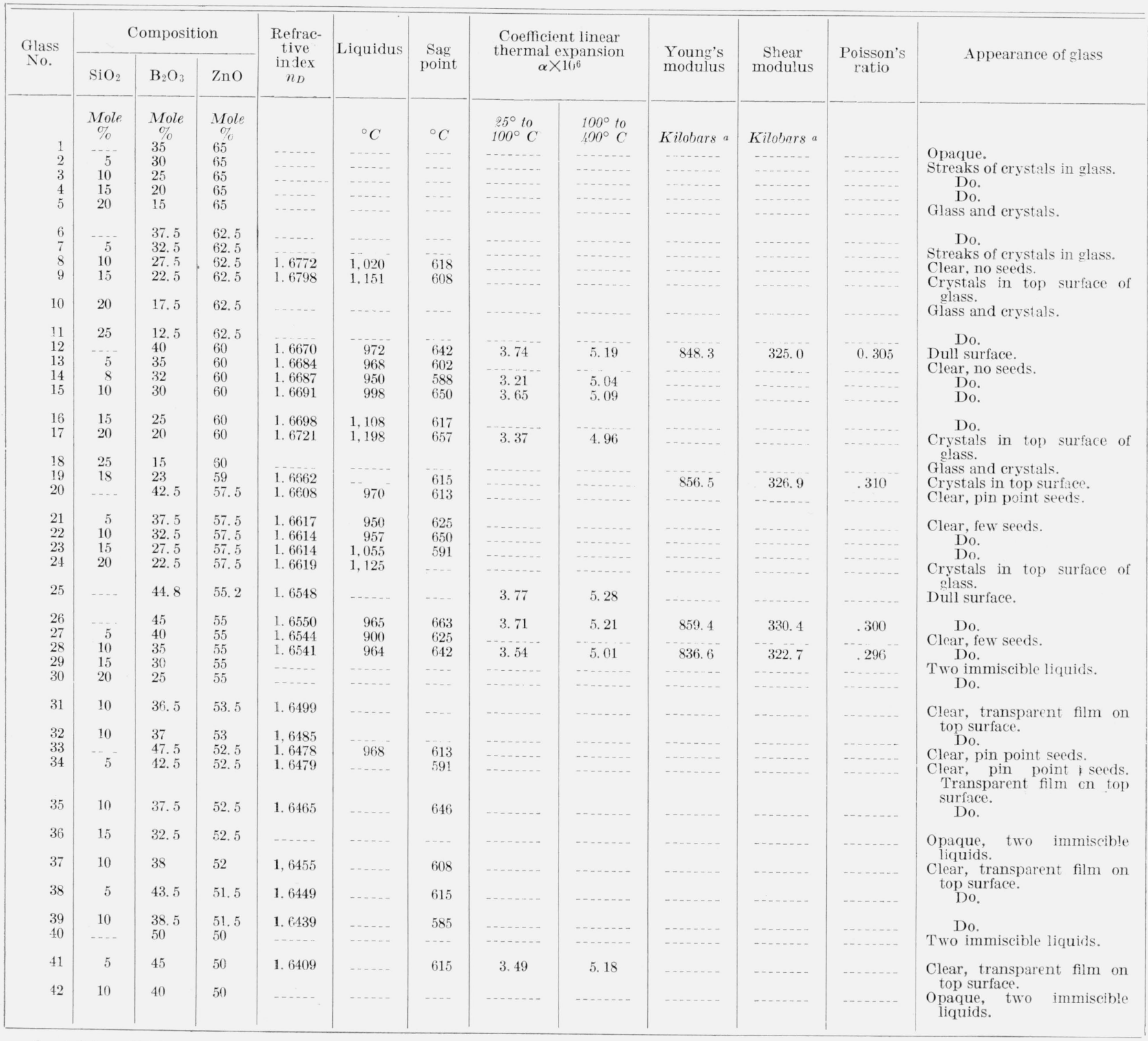

a One kilobar $=1 \times 10^{9} \mathrm{dynes} / \mathrm{cm}^{2}$.

TABLE 2. Comparison of analyzed and calculated compositions of selected glasses.

\begin{tabular}{|c|c|c|c|}
\hline Glass number & $\mathrm{ZnO}$ & $\mathrm{B}_{2} \mathrm{O}_{3} \mathrm{a}$ & $\mathrm{SiO}_{2}$ \\
\hline $\begin{array}{l}12\left\{\begin{array}{l}\text { Calculated } \\
\text { Analyzed }\end{array}\right. \\
16\left\{\begin{array}{l}\text { Calculated } \\
\text { Analyzed }\end{array}\right. \\
{ }_{26}\left\{\begin{array}{l}\text { Calculated } \\
\text { Analyzed }\end{array}\right. \\
28\left\{\begin{array}{l}\text { Calculated } \\
\text { Analyzed }\end{array}\right.\end{array}$ & $\begin{array}{l}\text { Mole \% } \\
60 \\
59.8 \\
60 \\
59.7 \\
55 \\
56.0 \\
55 \\
55.5\end{array}$ & $\begin{array}{l}\text { Mole \% } \\
\quad 40 \\
40.2 \\
25 \\
25.2 \\
45 \\
44.0 \\
35 \\
34.5\end{array}$ & \begin{tabular}{c} 
Mole \% \\
15 \\
15.1 \\
\hdashline 10 \\
10.0
\end{tabular} \\
\hline
\end{tabular}

a Analyzed values for $\mathrm{B}_{2} \mathrm{O}_{3}$ were obtained by difference. values are about $30^{\circ} \mathrm{C}$ lower than those reported by Ingerson et al. [2]. In either of these investigations, failure to obtain equilibrium or losses due to volatilization could account for such differences.

All the clear glasses, free from crystal defects on the surface or in the body of the glass, had liquidus temperatures between $900^{\circ}$ and $1,110^{\circ} \mathrm{C}$.

A melt of the composition $\mathrm{ZnO} \cdot \mathrm{B}_{2} \mathrm{O}_{3}$, No. 40, was opaque at pouring temperatures. After cooling it was discovered that the cast block consisted of a thin opaque shell surrounding a mass of clear, transparent glass. The $\mathrm{ZnO}$ contents of the transparent glass and the opaque shell were determined with the following results: transparent glass 52.3 mole percent, and opaque shell 0.9 mole percent. So it appears that the region of liquid immiscibility is slightly larger than indicated by Ingerson et al. 


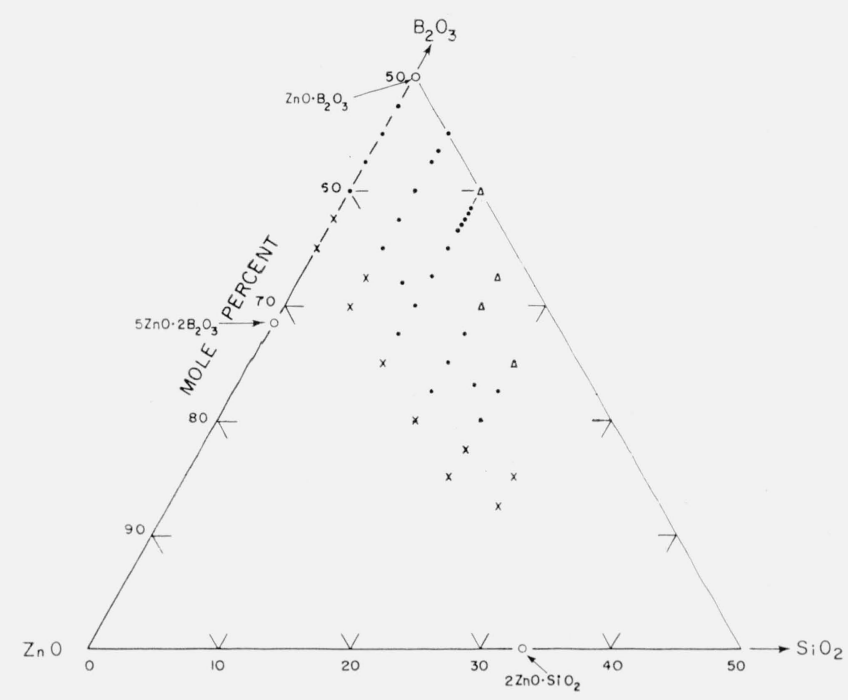

Figure 1. Compositions studied in the system $\mathrm{ZnO}-\mathrm{B}_{2} \mathrm{O}_{3}-\mathrm{SiO}_{2}$.

, One liquid, cooled to glass; $X$, one liquid, cooled to glass plus crystals; $\Delta$, wo immiscible liquids.

[2] and includes the compound composition $\mathrm{ZnO} \cdot \mathrm{B}_{2} \mathrm{O}_{3}$. The temperature at which the melt is fined and poured will determine whether a clear glass or two phases are obtained. For example, repeat melts of the No. 40 composition produced two immiscible liquids when the melts were fined and poured below $1,200^{\circ} \mathrm{C}$; and when melted and poured at $1,250^{\circ}$ to $1,300^{\circ} \mathrm{C}$, clear glasses were obtained indicating that at these temperatures only one liquid was present. When the clear glasses were heat-treated at temperatures above $957^{\circ} \mathrm{C}$ tiny globules appeared in the body of the glass, probably because of the separation of an immiscible liquid phase.

Zinc borosilicate glasses containing less than 55 mole percent of $\mathrm{ZnO}$ were characterized by the presence of thin films on the top surfaces of the cast blocks. These thin films produced interference colors when viewed by reflected light. The interference colors were visible immediately after the melt was poured. The thickness of the films varied across the surface of each glass as well as from glass to glass. Presumably the thin films result from the presence in the melt of two liquid phases which are immiscible at pouring temperatures.

\subsection{Refractive Indices}

The refractive indices of the annealed glasses are given in table 1 and are plotted against the $\mathrm{SiO}_{2}$ content of the glasses in figure 2. The effect upon the refractive indices of the introduction of $\mathrm{SiO}_{2}$ into zinc borate glasses varies with their $\mathrm{ZnO}$ contents. For glasses containing 57.5 mole percent or more of $\mathrm{ZnO}$, the refractive indices of the glasses increase with increase in $\mathrm{SiO}_{2}$ content and the rate of increase is determined by the $\mathrm{ZnO}$ content of the glasses. For glasses containing 55 mole percent or less of $\mathrm{ZnO}$, increasing the $\mathrm{SiO}_{2}$ content decreases the refractive index.

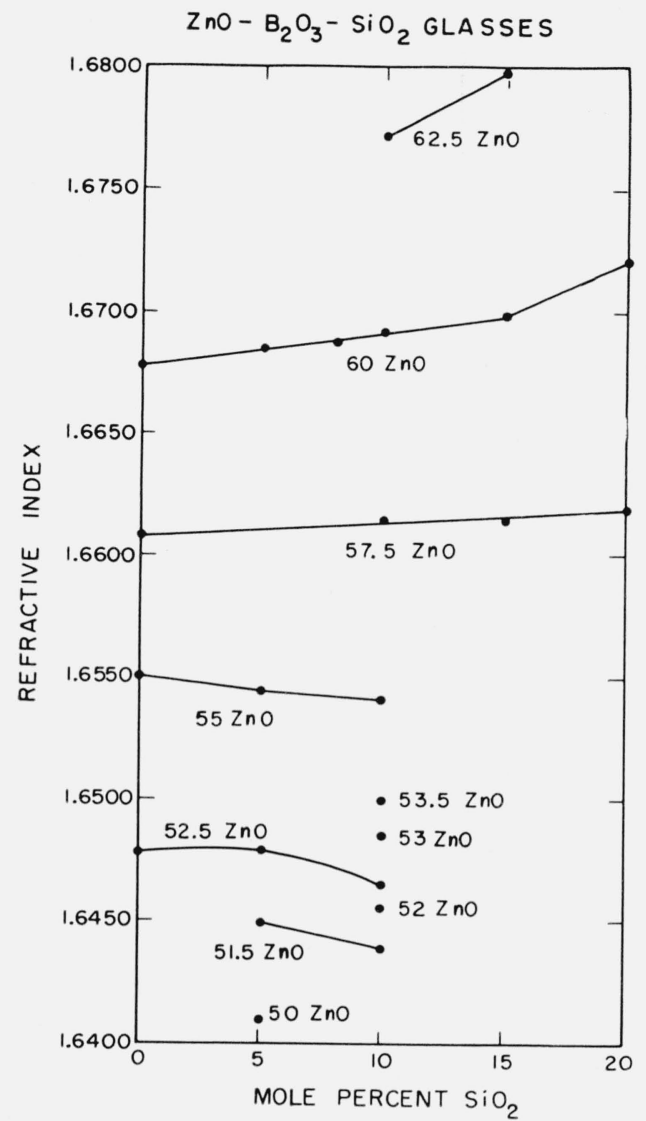

FiguRe 2. Change in refractive index with change in composition along $\mathrm{ZnO}$ isopleths.

The value adjacent to a line or a point indicates the $\mathrm{ZnO}$ content in mole percent.

\subsection{Thermal Expansion}

Three of the zinc borate glasses had cocfficients of thermal expansion in the temperature range of $25^{\circ}$ to $100^{\circ} \mathrm{C}$ which were essentially identical to that reported for Winklemann's glass. For the glasses containing $\mathrm{SiO}_{2}$ the coefficients were even lower and approached that of Corning's Pyrex Brand glass No. 7740. The coefficients of the glasses increased with temperature, but at higher temperatures were still considerably lower than for most commercial glasses which range from 7.0 to $10.0 \times 10^{-6}$.

\subsection{Elastic Moduli}

Elastic moduli were determined on four of the glasses by a dynamic method [12]. The specimens were in the form of bars ground to approximately $5 \frac{5}{8}$ by $1 \frac{1}{2}$ by $1 / 3$ in. in size. With bars of this size and shape the resonant frequencies for flexure and torsion were between 1,600 and $2,000 \mathrm{cps}$ and 3,400 and 4,000 $\mathrm{cps}$, respectively. The glasses have Young's moduli above 800 kilobars ${ }^{3}$ and Poisson's ratios of about 0.3 , both of which are higher than the values reported by Spinner [12] for common optical glasses. Poisson's ratio for most glasses is usually between 0.2 and 0.25 .

\footnotetext{
3 One kilobar is equivalent to $1 \times 10^{9} \mathrm{dynes} / \mathrm{cm}^{2}$.
} 
TABLE 3. Chemical durability of selected glasses

\begin{tabular}{|c|c|c|c|c|c|c|c|c|c|}
\hline \multirow{2}{*}{$\begin{array}{l}\text { Glass } \\
\text { No. }\end{array}$} & \multicolumn{3}{|c|}{ Composition } & \multicolumn{6}{|c|}{$\begin{array}{l}\text { Surface alteration in fringes, a at } p \mathrm{H} \text { : } \\
\left(\text { exposure, } 6 \mathrm{hr} \text { at } 80^{\circ} \mathrm{C}\right)\end{array}$} \\
\hline & $\mathrm{SiO}_{2}$ & $\mathrm{~B}_{2} \mathrm{O}_{3}$ & $\mathrm{ZnO}$ & 2 & 4 & 6 & 8 & 10 & 12 \\
\hline $\begin{array}{l}12 \\
26 \\
28\end{array}$ & $\frac{\text { Mole \% }}{10}$ & $\begin{array}{c}\text { Mole \% } \\
40 \\
45 \\
35\end{array}$ & $\begin{array}{c}\text { Mole \% } \\
60 \\
55 \\
55\end{array}$ & $\begin{array}{r}\text { Severe b.... } \\
\hdashline \\
\hdashline\end{array}$ & $\begin{array}{l}1.5 \\
0.6 \\
2.4\end{array}$ & $\begin{array}{r}0.1 \\
.1 \\
.2\end{array}$ & $\begin{array}{r}0.2 \\
.1 \\
.2\end{array}$ & $\begin{array}{r}\text { ND } \\
0.1 \\
\text { - ND }\end{array}$ & $\begin{array}{c}\text { Severe. } \\
\text { Do. } \\
\text { d } 0.1 \text { (SC). }\end{array}$ \\
\hline
\end{tabular}

a One fringe is approximately equivalent to depth of attack of $0.29 \mu$.

b Severe: Attack so great it was impossible to determine the surface alteration in terms of fringes.

- ND: Not detectable.

d SC: In addition to the indicated surface alteration there was severe attack at the air-liquid interface.

\subsection{Chemical Durability}

Using an interferometric method [11] the chemical durabilities of three of the glasses were determined in solutions buffered at $p \mathrm{H}$ values of $2,4,6,8,10$, and 12 . The results are given in table 3 . The addition of $\mathrm{SiO}_{2}$ to the zinc borate glasses did not improve the resistance to attack by acids but did increase the resistance to strong alkali. The results indicate that the glasses should be serviceable in the $p \mathrm{H}$ range of 6 to 10, inclusive.

A polished sample of glass No. 28 was exposed to alternate cycles of wetting and drying. Each cycle was of $30 \mathrm{~min}$. duration. During the wetting cycle the sample was heated from $60^{\circ}$ to $65^{\circ} \mathrm{C}$ while the humidity was maintained at the saturation point, then the temperature was lowered to $60^{\circ} \mathrm{C}$ and the relative humidity to 84 percent for the drying cycle. After $96 \mathrm{hr}$ exposure there was no detectable change in the appearance, light transmission, or weight of the polished plate.

\subsection{Surface Devitrification}

During annealing, the two component $\mathrm{ZnO}-\mathrm{B}_{2} \mathrm{O}_{3}$ glasses always developed a dull appearance on their exposed surfaces. The amount of this surface devitrification varied with the time and temperature of heat treatment. The three component glasses, containing as little as 5 mole percent of $\mathrm{SiO}_{2}$, always maintained a brilliant transparent surface during annealing. The tarnishing of the $\mathrm{ZnO}-\mathrm{B}_{2} \mathrm{O}_{3}$ glasses during heat treatment is probably one of the reasons why Winklemann's glass has not been adopted for commercial use. This tarnishing may be caused by a loss of $\mathrm{B}_{2} \mathrm{O}_{3}$ from the surface of the glass at the annealing temperature.

\section{Summary}

The glass-forming area of the system $\mathrm{ZnO}-\mathrm{B}_{2} \mathrm{O}_{3^{-}}$ $\mathrm{SiO}_{2}$ was surveyed. Clear glasses are obtained in or adjacent to the primary field of the compound $\mathrm{ZnO} \cdot \mathrm{B}_{2} \mathrm{O}_{3}$. This primary field is extremely flat, indicating a high degree of dissociation of the primary compound at the liquidus. Such a condition appears to be favorable for the formation of stable multicomponent glasses.
The glasses have moderately low thermal expansions and high values of elastic moduli and Poisson's ratio.

The authors thank Thomas Scuderi for determining the chemical durabilities of the glasses and H. A. Berman for making the chemical analysis.

\section{References}

[1] H. Hovestadt, Jena Glass, pp. 146, 193, and 216 (MacMillan and Co., Ltd., London, 1902).

[2] E. Ingerson, G. W. Morey, and O. F. Tuttle, The systems $\mathrm{K}_{2} \mathrm{O}-\mathrm{SiO}_{2}, \mathrm{ZnO}-\mathrm{B}_{2} \mathrm{O}_{3}-\mathrm{SiO}_{2}$, and $\mathrm{Zn}_{2} \mathrm{SiO}_{4}-\mathrm{Zn}_{2} \mathrm{GeO}_{4}, \mathrm{Am}$. J. Sci. 246, 31 (1948).

[3] E. H. Hamilton and G. W. Cleek, The shape of the liquidus surface as a criterion of stable glass formation, J. Research NBS 60, 593 (1958) RP2872.

[4] E. N. Bunting, Phase equilibria in the system $\mathrm{SiO}_{2}-\mathrm{ZnO}$, BS J. Research 4, 131 (1930) RP136; J. Am. Ceram. Soc. 13, 5 (1930).

[5] G. W. Cleek and E. H. Hamilton, Properties of barium titanium silicate glasses, J. Research NBS 57, 317 (1956) RP2720.

[6] E. H. Hamilton, G. W. Cleek, and O. H. Grauer, Some properties of glasses in the barium oxide-boric oxidesilica system, J. Am. Ceram. Soc. 41, 209 (1958).

[7] S. Spinner, G. W. Cleek, and E. H. Hamilton, Determination and use of the sag point as a reference point in the heating of glasses, J. Research NBS 59, 227 (1957) RP2791.

[8] O. H. Grauer, Precision refractometer-U. S. Patent No. 2,772,597 (December 4, 1956).

[9] O. H. Grauer and E. H. Hamilton, An improved apparatus for the determination of liquidus temperature and rates of crystal growth in glass, J. Research NBS, 44, 495 (1950) R P2096.

[10] J. B. Saunders, An apparatus for photographing interference phenomena, J. Research NBS 35, 157 (1945) RP1668.

[11] D. Hubbard and E. H. Hamilton, Studies of the chemical durability of glass by an interferometer method, J. Research NES 27, 143 (1941) RP1409.

[12] S. Spinner, Elastic moduli of glasses by a dynamic method, J. Am. Ceram. Soc. 37, 231 (1954).

Washington, October 27, 1958. 